\title{
Drug adherence among adult hypertensives attending medical out-patient clinic in a tertiary hospital in Ogun State, Nigeria
}

\author{
Bamidele $E^{1}$, Sodeinde $K^{1}$, Adefala $K^{1}$, Osinaike $A^{1}$, Omotosho $A^{1}$ \\ ${ }^{1}$ Department of Community Medicine, Babcock University, Ilishan, Ogun State, Nigeria
}

\begin{abstract}
Objective: The research aimed to estimate the level of drug adherence, to determine the reasons for nonadherence, and identify risk factors associated with non -adherence among adult hypertensive clients attending an out-patient clinic in Ogun State, Nigeria.

Methodology: A descriptive cross-sectional study of adults with hypertension at a medical outpatient clinic in a tertiary hospital. Four hundred and four (404) respondents were selected from November 2015 to April 2016, a validated questionnaire by Morisky Green was adapted and distributed by trained research assistants. The chisquare test was used to compare categorical variables like sex, marital status, and clinic attendance among the two groups of adherent and non-adherent hypertensive. Information was summarized using frequency tables and cross-tabulations. Binary logistic regression analysis was done. The level of significance was set at $5 \%$.

Results: Optimal adherence was observed in $281(69.0 \%)$ of the respondents. Being a female (OR: 1.833; 1.048 $7.205, p=0.034$ ), being employed (OR: 2.099; 1.097-4.096, $p=0.03$ ) and regular clinic attendance (OR: 22.26; $12.647-39.107, p<0.001)$ were significantly correlated with optimal adherence. Forgetfulness $(23,9.9 \%)$, use of traditional medicines $(42,18.1 \%)$, lack of funds $(59,25.4 \%)$, and feeling well $(60,25.9 \%)$ were some of the reasons for suboptimal adherence.

Conclusion: The level of drug adherence among the respondents was good, especially among those that attend clinics regularly, those that are employed, and female respondents. Suboptimal adherence among the few respondents was due to forgetfulness, the use of traditional medicine, lack of funds, and stopping the use of drugs when they felt better.
\end{abstract}

Key Words: Adherence, Anti-hypertensive therapy, Medical Out-Patient department.

\section{Background}

Hypertension or high blood pressure is when the systolic blood pressure is greater or more than $140 \mathrm{mmHg}$ and the diastolic blood pressure is greater than or more than $90 \mathrm{mmHg}$, measured at least twice six hours apart $(1,2)$. It is a global problem reported as the third leading cause of disability-adjusted life-year (DALY) $(1,2)$. Result of the global burden of hypertension showed that $31.1 \%$ of the adult population in the world had high blood pressure in the year 2010 (3). The prevalence of hypertension is higher in low and middle-income countries $(31.5 \%)$ than in high- income countries (28.5\%) (3). Seventy-five (75\%) people with high blood pressure (1.04 billion) live in low-and-middle-income countries (3). The prevalence of hypertension continued to rise in countries like Nigeria. There was a $7.7 \%$ increase in hypertension prevalence in low-and-middleincome countries within 10 years (2000 to 2010) compared with a $2.6 \%$ reduction in high-income countries (3). The frequency of high blood pressure in Nigeria is said to be at an alarming rate, where $40-45 \%$ of adults are said to be hypertensive from various studies across Nigeria $(4,5)$. Also, several studies have shown that 
controlled blood pressure is associated with a decrease in the incidence of cardiovascular accident and hypertensive heart diseases $(4,5)$. Medication adherence is the medication-taking attitude of a patient who agrees with instruction from a health care worker (6). It is an important factor in achieving optimum blood pressure control. It is related to many factors which include patient history, demographics, poly-pharmacy, stages of the disease and patients' forgetfulness (7).

Despite the availability of drugs, treatment model plan, and availability of healthcare workers, medication adherence failure remains one of the problems of controlling high blood pressure generally $(8,9)$. Negligence on the part of the patients to prescribed medications can result in complications arising from the disease, reduce patient's standard of living, puts a heavy burden on scarce health care resources and cast doubt on the integrity of the health systems (5).

An estimated 14.55 million people worldwide between the ages of 30 to 80 years were reported to have died as a result of hypertension-related conditions in 2008; while $7.03 \%$ of this was reported for sub-Saharan Africa (10). The total estimated deaths resulting from all cardiovascular diseases and hypertensive heart disease recorded for Nigeria by WHO were 201,500 and 10,700 respectively and placed Nigeria in the 16th position globally.

Similarly, the disability-adjusted life years (DALYs) lost to cardiovascular diseases and hypertensive heart disease reported for Nigeria in was $2,116,000$ and 105,000 respectively and puts Nigeria in the first position in sub-Saharan Africa (5).

Poor adherence to antihypertensive medications has been linked with increased cardiovascular risk and mortality in many populations. Blacks have been shown to have a worse prognosis from hypertension, poorer blood pressure control, and increased risk of complications arising from hypertension compared to Caucasians (3).

This study aims to determine the level of adherence to antihypertensive medications among adult hypertensive patients attending a medical outpatient clinic in Babcock University Teaching Hospital (BUTH) and identify risk factors associated with poor adherence among the study participants.

\section{Methodology}

It is a cross-sectional study carried out at Babcock University Teaching Hospital. The hospital is located in Ilishan-Remo in Ikenne
Local Government Area of Ogun State, Nigeria. The study populations are adult patients with hypertension, on antihypertensive therapy for at least six months accessing care at Babcock University Teaching Hospital. A total of 404 respondents were enrolled involving all patients who attended the hypertension clinic from 9 am to $2 \mathrm{pm}$ every Tuesday and Thursday in the hospital from November 2015 to April 2016.

A validated questionnaire (9) was adapted to the study setting and used to assess medication adherence. It consisted of five sections. Section A contained questions on demographics, while segment $B$ assessed adherence of hypertensive patients to the treatment regimen (4 items) and reasons for non-adherence (8 items). Sections $C$ and $D$ assessed respondent practice relating to hypertension (9 items), while Segment E assessed lifestyle and dietary modification (5 items).

The protocol for Morisky-Green test compliance to hypertension therapy was used to ascertain respondents' adherence to hypertension therapy with the answering options of "Yes" and "No". The scale was designed to evaluate medication adherence in patients with hypertension and it has been validated and found to be reliable in a variety of medication adherence studies. Adherence was based on four (4) questions; the correct answer is allocated a mark of 1 while the wrong answer is not allocated any mark (zero). Respondents that answered at least 3 questions or scored a minimum of $75 \%$ were adjudged to have good adherence, while respondents that scored below $75 \%$ were adjudged to have poor adherence.

Data were entered into the computer using Statistical Package for Social Sciences (SPSS) version 22. Demographic information was summarized using frequency tables and crosstabulations, while categorical variables like sex, marital status, and clinic attendance among the two groups of adherent and non-adherent hypertensive were tested using the chi-square test. Also, Binary logistic regression analysis was done, a P-value of $\leq 0.05$ was regarded as statistically significant.

\section{Results}

Table 1 shows the demographic characteristics of the participants. The mean age of the respondents was $59.8 \pm 15.0$ years. There was more female than male participants $(61.6 \%>$ $38.4 \%)$. The majority of them were married (244, $60.4 \%)$ and overweight $(171,42.3 \%)$. A few respondents $(35,8.7 \%)$ had no form of formal 
education, while about one-third (130, 32.2\%) had tertiary education. Most of them were employed, with an income of less than 20,000 Naira per month. Among all the respondents sampled, $(135,33.4 \%)$ within 5 years preceding the study. The cost of treatment was below N5, 000 monthly in the majority $(242,59.9 \%)$ of the patients. Few of the respondents smoked cigarettes $(55,13.5 \%)$ and consumed alcohol $(91,22.5 \%)$.

Table 1: Socio-demographic Characteristics of Respondents

\begin{tabular}{|c|c|c|}
\hline Variables & Frequency $(n=404)$ & Percentage (\%) \\
\hline \multicolumn{3}{|l|}{ Age group (Years) } \\
\hline $26-35$ & 18 & 4.5 \\
\hline $36-45$ & 50 & 12.4 \\
\hline $46-55$ & 96 & 23.8 \\
\hline $56-65$ & 97 & 24.0 \\
\hline $66-75$ & 69 & 17.1 \\
\hline $76-85$ & 52 & 12.9 \\
\hline$\geq 86$ & 22 & 5.4 \\
\hline \multicolumn{3}{|l|}{ Sex } \\
\hline Male & 155 & 38.4 \\
\hline Female & 249 & 61.6 \\
\hline \multicolumn{3}{|l|}{ Marital status } \\
\hline Single & 16 & 4 \\
\hline Married & 244 & 60.4 \\
\hline Divorced & 41 & 10.1 \\
\hline Widow & 51 & 12.6 \\
\hline Separated & 52 & 12.9 \\
\hline \multicolumn{3}{|l|}{ Education level } \\
\hline No formal education & 35 & 8.7 \\
\hline Primary & 86 & 21.3 \\
\hline Secondary & 153 & 37.9 \\
\hline Tertiary & 130 & 32.2 \\
\hline \multicolumn{3}{|l|}{ Occupation } \\
\hline Employed & 182 & 45.0 \\
\hline Unemployed & 99 & 24.5 \\
\hline Self-employed & 123 & 32.2 \\
\hline \multicolumn{3}{|c|}{ Monthly income (Naira) } \\
\hline Below 20,000 & 160 & 39.6 \\
\hline $20,000-49,0000$ & 153 & 37.9 \\
\hline $50,000-100,000$ & 72 & 17.8 \\
\hline$>100,000$ & 19 & 4.7 \\
\hline \multicolumn{3}{|l|}{ Smoking } \\
\hline Yes & 55 & 13.6 \\
\hline No & 349 & 86.4 \\
\hline \multicolumn{3}{|l|}{ Alcohol use } \\
\hline Yes & 91 & 22.5 \\
\hline No & 313 & 77.5 \\
\hline \multicolumn{3}{|l|}{ BMI status $\left(\mathbf{k g} / \mathrm{m}^{2}\right)$} \\
\hline Underweight & 5 & 1.2 \\
\hline Normal & 139 & 34.4 \\
\hline Overweight & 171 & 42.3 \\
\hline Obese & 89 & 22.0 \\
\hline
\end{tabular}

Mean Age: $59.8 \pm 15.0$

Table 2 shows that $135(33.4 \%)$ of the participants were discovered to have elevated blood pressure in the past five years and were placed on at least 2-3 drugs per day, with a monthly cost of medication between five and ten thousand Naira. One hundred and thirty-nine $(34.4 \%)$ of the participants had other medical conditions they were being treated for. However, 
most of them $310(76.7 \%)$ monitored their (BP) blood pressure regularly, while over a third (149,
$36.9 \%$ ) had a history of admission since being diagnosed hypertensive.

Table 2: History of Hypertension and other medical conditions

\begin{tabular}{lcc}
\hline \multicolumn{1}{c}{ Variable } & Frequency $(\mathbf{n = 4 0 4 )}$ & Percentage (\%) \\
\hline When hypertension was diagnosed & & \\
1 year & 85 & 21.0 \\
2 years & 92 & 22.8 \\
2-5years & 135 & 33.4 \\
5 years & 92 & 22.8 \\
No of different types drugs & 3 & \\
None & 55 & 0.7 \\
$1-2$ & 143 & 13.6 \\
$2-3$ & 126 & 35.4 \\
$3-4$ & 77 & 31.2 \\
>4 & & 19.1 \\
Monthly cost of medication in (Naira) & 242 & \\
Below 5000 & 155 & 59.9 \\
$5,000-10,000$ & 6 & 38.4 \\
$10,000-50,000$ & 1 & 1.5 \\
50,000 & & 0.2 \\
Other Medical condition & 139 & 34.4 \\
Yes & 265 & 65.6 \\
No & & \\
History Of Admission Since Diagnosed & 149 & 36.9 \\
Yes & 255 & 63.1 \\
No & & \\
Monitor BP regularly & 310 & 76.7 \\
Yes & 94 & 23.3 \\
No & & \\
\hline
\end{tabular}

Table 3 shows that $281(69.6 \%)$ of the participants' had good adherence to medication. Most of the respondents $277(68.6 \%)$ attended clinics regularly, while $127(31.4(\%)$ were not regular with their clinic visits. The main reasons for poor drug adherence were ignorance (stopped medicine when feeling well; $60,25.9 \%$ ), lack of funds to purchase drugs $(50,25.4 \%)$, traditional medicine usage $(42,18.1 \%)$. The other factors include forgetfulness $(23,9.9 \%)$, tired of medications $(17,7.3 \%)$, busy work schedule $(13$, $5.6 \%)$, side effects of medication $(10,4.3 \%)$, and use of multiple drugs $(8,3.4 \%)$.

Table 3: Regularity at Clinic and adherence of patients to the hypertensive treatment regimen

\begin{tabular}{lcc}
\multicolumn{1}{c}{ Variable } & Frequency $(\mathbf{n = 4 0 4 )}$ & Percentage(\%) \\
\hline Regularity at Clinic & & \\
Regular & 277 & 68.6 \\
Not regular & 127 & 31.4 \\
Adherence level & & \\
Good & 281 & 69.6 \\
Poor & 123 & 30.4 \\
\hline$\quad$ Reasons for Non Adherence & Frequency(n=123) & Percentage (\%) \\
\hline Stop medicine when feeling well & 60 & 25.9 \\
No money & 59 & 25.4 \\
Using traditional medicine & 42 & 18.1 \\
Forgetfulness & 23 & 9.9 \\
Tired of the drugs & 17 & 7.3 \\
Busy work schedule & 13 & 5.6 \\
Side effects of medication & 10 & 4.3 \\
Drugs are too many & 08 & 3.4 \\
\hline
\end{tabular}

${ }^{*}$ : multiple responses 
Table 4 reveals the women $(76.7 \%)$ had a higher proportion of drug adherence than the male $(58.1 \%)$ participants $(x 2=15.678, \quad p=0.0001)$. Also, respondents who attended clinics regularly have good adherence compared to respondents who do not attend clinics regularly $(61.1 \%$ vs. $8.4 \% ; p=0.0001)$; and respondents that are employed were more adherent than the unemployed $(x 2=8.522, p=0.014)$. Association between drug adherence and marital status $(x 2=4.439, \quad p=0.350)$, education $\quad(x 2=3.577$, $p=0.311)$, age $(x 2=4.492, p=0.610)$, and income $(x 2=1.839, p=0.607)$ were not significant.

Table 4: Factors associated with adherence to antihypertensive drugs among respondents in Babcock University Teaching Hospital.

\begin{tabular}{|c|c|c|c|c|}
\hline Variable & Adherence Status & & $x^{2}$ & P-Value \\
\hline & Adherence $(n=281)$ & Non-adherence $(n=123)$ & & \\
\hline \multicolumn{5}{|l|}{ Sex } \\
\hline Male & $90(22.3 \%)$ & $65(16.0 \%)$ & & \\
\hline Female & $191(47.3 \%)$ & $58(14.4 \%)$ & 15.678 & $<0.001$ \\
\hline \multicolumn{5}{|l|}{ Marital Status } \\
\hline Single & $09(2.2 \%)$ & $07(1.7 \%)$ & & \\
\hline Married & $172(42.6 \%)$ & $72(17.8 \%)$ & & \\
\hline Divorced & $32(7.9 \%)$ & $09(2.2 \%)$ & & \\
\hline Widow & $36(8.9 \%)$ & $15(3.7 \%)$ & & \\
\hline Separated & $32(7.9 \%)$ & $20(5.1 \%)$ & 4.439 & 0.350 \\
\hline \multicolumn{5}{|l|}{ Educational } \\
\hline \multicolumn{5}{|l|}{ Status } \\
\hline $\begin{array}{l}\text { No formal } \\
\text { education }\end{array}$ & $28(6.9 \%)$ & $07(1.7 \%)$ & & \\
\hline Primary & $59(14.6 \%)$ & $27(6.7 \%)$ & & \\
\hline Secondary & $100(24.8 \%)$ & $53(13.1 \%)$ & & \\
\hline Tertiary & $94(23.3 \%)$ & $36(8.9 \%)$ & 3.577 & 0.311 \\
\hline \multicolumn{5}{|l|}{ Occupation } \\
\hline Employed & $114(28.2 \%)$ & $68(16.8 \%)$ & & \\
\hline Unemployed & $71(17.6 \%)$ & $28(6.9 \%)$ & & \\
\hline Self-employed & $96(23.8 \%)$ & $27(6.7 \%)$ & 8.522 & 0.014 \\
\hline \multicolumn{5}{|l|}{ Monthly Income } \\
\hline$<20,000$ & $110(27.2 \%)$ & $50(12.4 \%)$ & & \\
\hline $20-49,000$ & $107(26.5 \%)$ & $46(11.4 \%)$ & & \\
\hline $50,000-100,000$ & $53(13.1 \%)$ & $19(4.7 \%)$ & & \\
\hline$>100,000$ & $11(2.7 \%)$ & $08(2.0 \%)$ & 1.839 & 0.607 \\
\hline \multicolumn{5}{|l|}{ Age group } \\
\hline $25-35$ & $11(2.7 \%)$ & $07(1.7 \%)$ & & \\
\hline $36-45$ & $35(8.7 \%)$ & $15(3.7 \%)$ & & \\
\hline $46-55$ & $63(15.6 \%)$ & $33(8.2 \%)$ & & \\
\hline $56-65$ & $68(16.8 \%)$ & $29(7.2 \%)$ & & \\
\hline $66-75$ & $46(11.4 \%)$ & $23(5.7 \%)$ & & \\
\hline $76-85$ & $40(9.9 \%)$ & $12(2.9)$ & & \\
\hline $86-95$ & $18(4.5 \%)$ & $04(1.0 \%)$ & 4.492 & 0.610 \\
\hline \multicolumn{5}{|l|}{ Ethnicity } \\
\hline Yoruba & $222(55 \%)$ & $89(22.0 \%)$ & & \\
\hline Igbo & $56(13.9 \%)$ & $27(6.7 \%)$ & & \\
\hline Hausa & $02(0.5 \%)$ & $05(1.2 \%)$ & & \\
\hline Others & $01(0.2 \%)$ & $02(0.5 \%)$ & 8.859 & 0.065 \\
\hline \multicolumn{5}{|c|}{ Clinic attendance } \\
\hline Regular & 247 (61.2) & $30(7.4)$ & & \\
\hline Not regular & $34(8.4)$ & $93(23.0)$ & 160.1 & $<0.001$ \\
\hline
\end{tabular}


Table 5 shows that being a female (OR: 1.833; $95 \%$; C. I: $1.048-7.205, \quad p=0.034)$, being employed (OR: 2.099; 95\% C.I: 1.097-4.096, $\mathrm{p}=0.03$ ), and regular clinic attendance (OR:22.26;
95\% C.I: 12.647-39.107, $p<0.001$ ) were significantly correlated with good drug adherence.

Table 5: Multivariate logistic regression of risk factors associated with adherence to hypertensive therapy

\begin{tabular}{llrc}
\hline \multicolumn{1}{c}{ Adherence variables } & Adjusted OR & \multicolumn{1}{c}{$\mathbf{9 5 \%} \mathbf{C l}$} & P-Value \\
\hline Female & 1.833 & $1.048-3.205$ & 0.034 \\
Employed & 2.099 & $1.097-4.096$ & 0.030 \\
Regular Clinic Attendance & 22.262 & $12.647-39.187$ & $<0.001$ \\
\hline
\end{tabular}

\section{Discussion}

This study was carried out to determine the level of adherence and factors affecting adherence to anti-hypertensive therapy among adult hypertensive patients attending Babcock University Teaching Hospital, Ilishan-Remo Ogun state, Nigeria. The mean age of study respondents was 59.8 years; the age is not surprising because high blood pressure is found among the elderly population. Similar to research done to assess the element influencing the adherence to anti-hypertensive care, which showed that the mean age of hypertensive patient 58.1 years (11). The level of adherence to anti-hypertensive therapy found by this research was $69 \%$, the level of adherence observed is higher than what was reported in similar studies in Ibadan $(51 \%)$ and Kano $(54.2 \%)(12,13)$, but lower than the values reported in Scotland and Pakistan (77\% and $91 \%)$ respectively (14).

The reason for a higher level of adherence in this study may be because more than half of the patients were employed, some of them were working at Babcock University. Eighty percent $(80 \%)$ of them had formal education that implies they know the reasons why they are placed on medications and the implications of not using the drugs. Another important reason for such level of adherence is that all the Babcock university staff that were receiving care in the hospital were on health insurance, this will motivate them to be more adherent to medications and clinic visits compared to the study in Ibadan and Kano with a lower level of adherence. The study participants in Ibadan are of low socioeconomic status with a low level of education, the majority $(26.0 \%)$ of them had no work or are retirees while the study in Kano shows that less than thirty percent of the participants had formal education and earned less than ten thousand Naira $(10,000)$ per month. The present study showed that $30.4 \%$ of the participants had poor adherence. The study showed that lack of money to buy prescribed drugs, the use of many drugs per day, side effects of medications, busy work schedules, forgetfulness, and use of traditional medicine were some of the reasons for poor adherence. The majority $(59.9 \%)$ of the respondents spent a lot of money on drugs which is one of the reasons for poor adherence. Nigeria is a developing country with people living below one dollar a day, therefore, spending much on anti-hypertensive drugs every month may be difficult especially for some patients who are self-employed or unemployed and eventually leads to poor adherence as reported in this study. This is similar to other studies in Nigeria (14). The study from Ibadan also identified lack of money, use of unorthodox medication, polypharmacy, and feeling well as constraints to adherence (15). The correlation between poor adherence and lack of money to buy drugs was also documented in another study by Isezuo and Opara in Sokoto (16). Socioeconomic factors of drug nonadherence, such as medication cost and lack of availability of drugs, are also essential factors for drug adherence. In developing countries like Nigeria where supplies of medications are limited at all levels of care, drug adherence could be improved by enhancing access to drugs by sustainable financing, affordable prices, and reliable supply systems.

Another reason for poor adherence is the use of two or more drugs by patients. $67 \%$ of the study participants were using two to four (2-4) drugs in a day every month. High blood pressure is a chronic disease with lifelong use of medication, using a lot of drugs can be inconvenient and depressing and as such contributes to poor adherence. Therefore, the use of fixed-dose drugs which is a model used in managing tuberculosis clients should be encouraged among hypertensive patients to reduce polypharmacy and promote adherence among hypertensive patients.

In this study, factors with a significant association with good drug adherence are female sex and regular clinic attendance. The majority of the 
respondents attended cardiovascular clinics faithfully, the perceived good adherence in the group is not unexpected since they are also more likely to follow other directives.

Female respondents were found to be more adherent with antihypertensive therapy than males. This is supported by a similar study (17), which found that patient's adherence to hypertensive medication was significantly lower in male patients. Impotence is one of the likely side effects which affect men on hypertensive medications, this might be the reason why males had a low level of adherence compared to females (18). Identifying patients who have problems with adherence in a population enables more targeted efforts toward improvement. For example, male respondents can be targeted.

The study also shows that respondents with higher education were more adherent compared to respondents who are not educated; this is similar to a study that found out that patients with higher education levels might have higher adherence (13). So identifying a factor that determines poor adherence of hypertensive patients to therapy is, therefore, of vital importance in applying therapeutic strategy and in obtaining satisfactory results $(17,19)$. Poor adherence compounds the challenges of improving health in poor populations and results in waste and underutilization of already limited treatment resources. Based on the results of this study, there is a need to set in motion a complete approach to involve health care workers, clients, and the general populace to educate patients on the importance of taking their drugs as prescribed. Also, health care workers should put in mind the financial status of their patients when they are prescribing drugs. This will facilitate affordability and adherence.

Some of the limitations of this study; is that the level of adherence reported was self-reported and there might be recall bias by the respondents. Also, consecutive recruitment of respondents is another limitation of this study.

\section{Conclusion}

The level of drug adherence among the respondents was good, especially among the regular clinic attendees, those that are employed and females. Poor adherence among the few respondents was due to forgetfulness, use of traditional medicine, lack of funds and few stopped using drugs when they felt that their symptoms had resolved. Male sex, unemployment, and patients who do not attend clinics regularly are risk factors for nonadherence noted among the respondents.

\section{Recommendation}

1. Patients need advice, support, and information from health professionals to be able to understand the importance of using drugs as prescribed.

2. Doctors and other health care workers must educate hypertensive patients about their disease on the importance of complying with hypertensive medications, the consequences of non-compliance with treatment.

3. Patients should be told that the drugs are for life and the disadvantage of skipping the dose. Hypertensive patients in BUTH should be counseled every time whenever they visit a physician to improve their adherence to antihypertensive therapy, thereby having better control of hypertension.

4. Health practitioners should be involved in developing models that will always remind patients to take their medications regularly without forgetting it, for example, an electronic monitoring device should be provided for patients to reduce patient's forgetfulness and enhance compliance to hypertensive treatment at a low cost.

5. The cost of anti-hypertensive drugs should be subsidized where possible, prescribing an effective, inexpensive with minimal side effects will improve patient compliance considerably.

\section{List of Abbreviations}

DALY: Disability Adjusted Life Year

OR: Odds Ratio

SDA: Seventh Day Adventist

SPSS: Scientific Package for Social Sciences

WHO: World Health Organization

\section{Declarations}

Ethics approval and consent to participate

Ethical approval was obtained from the Babcock University Health Research Ethics Committee (BUHREC 548/16.). Written informed consent was obtained from the respondents and strict confidentiality of all information and findings was maintained throughout the study.

\section{Consent for Publication}

The authors hereby transfer all copyright ownership exclusively to the journal, if this work is published by the journal.

Conflicts of Interest

The authors have declared no conflict of interest. 


\section{Funding}

The authors received no research funding.

\section{Authors Contributions}

EB conceived the research idea and wrote the first draft. All authors drafted the manuscript and approved the final submission.

\section{References}

1. Go AS, Mozaffarian D, Roger VL, Benamin EJ, Berry JD, Blaha MJ et al. Heart disease and stroke statistics-2014 update: a report from the American Heart Association. 2014;129(3): e28-292.

2. Aronow WS. Treatment of systemic hypertension. Am J Cardiovasc Dis. 2012;2(3):160-170.

3. Mills KT, Bundy JD, Kelly TN, Reed JE, Kearney PM, Reynolds K. Global Disparities of Hypertension Prevalence and Control: Systematic Analysis of Population Based Studies from 90 Countries. American Health Association Journal.2016; 134(6):441-450. https://doi.org/10.1161/circulationaha.115.01 8912

4. Heidenreich PA. Patient adherence: the next frontier in quality improvement. Am J Med. 2004; 117(2):73-81.

5. Akintunde AA, Ayodele OE, Akinwusi PO, Opadijo GO. Metabolic syndrome: Comparison of occurrence using three definitions in hypertensive patients. Clinical Medical Review. 2011; 9(1):26-31. https://doi.org/10.3121/cmr.2010.902

6. Burhart PV, Sabaté E. Adherence to long-term therapies: evidence for action. J Nurs Scholarsh.2003;(3):207.

7. Ho PM, Magid DJ, Shetterly SM, Olson KL, Maddox TM, Peterson PN et al. Medication non-adherence is associated with a broad range of adverse outcomes in patients with coronary artery disease. Am Heart J. 2008; 155(4): 589-590. https://doi.org/10.1016/j.ahj.2007.12.011

8. Kearney P, Whelton M, Reynolds K., Whelton P. Global burden of hypertension: analysis of worldwide data. Lancet 2005;36(5): 217-23. https://doi.org/10.1016/s01406736(05)17741-1

9. Morisky DE, Ang A, Krousel-Wood M, Ward HJ. Predictive validity of a medication adherence measure in an outpatient setting. $J$ Clin Hypertens (Greenwich) 2008; 10:348-54. https://doi.org/10.1111/i.1751$\underline{7176.2008 .07572 . x}$
10. Osamor PE, Owumi E. Factors Associated with Treatment Compliance in Southwest Nigeria. Journal of Health, Population and Nutrition.2011;29(6):619-628.

https://doi.org/10.3329/jhpn.v29i6.9899

11.Almas, A., Hameed, A., Ahmed, B., \& Islam, M. Compliance to antihypertensive therapy. JCPSP. 2006;16(1): 23-26.

12. Olubodun J.O, Falase A.O, Cole T.O. Drug compliance in hypertensive Nigerians with and without heart failure. International Journal of Cardiology. 1990; 27(2): 229-34. https://doi.org/10.1016/0167-5273(90)90164z

13. Kabira M; Compliance to medication among hypertensive patients in Murtala Mohammed specialist Hospitals, Kano, Nigeria. Journal of Community Medicine and Primary Health care.2004; 16(1):16-20. https://doi.org/10.4314/jcmphc.v16i1.32401

14. Hashmi K, Afridi M, Abbas K, Sajwani A, Saleheen D, Philippe M., et al. Factors Associated with Adherence to AntiHypertensive Treatment in Pakistan. PLoS ONE 2007; 2 (3): e280. https://doi.org/10.1371/journal.pone.0000280

15. Akpa MR, Agomuoh DI, Odia OJ. Drug compliance among hypertensive patients in Port Harcourt Nigeria. Nigeria Journal. Medicine. $\quad$ 2005;14(1): 55-57. https://doi.org/10.4314/njm.v14i1.37136

16. Isezuo AS, Opara TC. Hypertension awareness among Nigerians in Tertiary health institution. Sahel Medical Journal. 2000; 3(2): 93-97.

17. Javaroni V, Neves MF. Erectile Dysfunction and Hypertension: Impact On Cardiovascular Risk and Treatment. International Journal of Hypertension. Volume 2012/Article ID/627278,11pages.

https://doi.org/10.1155/2012/627278

18. Schoberger $\mathrm{R}$. The compliance praxis survey (compress): a multidimensional instrument to monitor compliance for patients on antihypertensive medication. J Hum Hypertens. 2002;16(11):779 - 87. https://doi.org/10.1038/sj.jhh.1001479

19.Andrude JP. Epidemiological Aspect of adherence to the treatment of Hypertension. Arq Bras Cardiol. 2002; 79(4): 775 - 84. 